\title{
Social Structural Influences on Emotional Support From Parents Early in Life and Adult Health Status
}

\author{
Benjamin A. Shaw, PhD, MPH; Neal Krause, PhD; Linda M. Chatters, PhD; \\ Cathleen M. Connell, PhD; Berit Ingersoll-Dayton, $\mathrm{PhD}$
}

\begin{abstract}
The authors' purpose in this study was to identify social structural predictors of receiving emotional support from parents early in life and structural factors responsible for variations in the associations between early parental support and adult health status. Data from a US representative sample of 2,786 adults aged 25-74 years suggest that men, non-Whites, and individuals from socioeconomically advantaged families report having received higher levels of early parental support. Furthermore, these analyses suggest that although adult health status is predicted by early parental support in general, health status among adults is particularly sensitive to levels of support received from a same-sex parent during childhood. These findings emphasize the pervasive influence of gender in American society and add focus to researchers'understanding of the long-term health effects of early parental support.
\end{abstract}

Index Terms: adult health, gender, parental support, race, socioeconomic status

Social structural factors, such as gender, race, and socioeconomic status (SES), exert profound and fundamental influences on health. ${ }^{1}$ Perhaps these influences are evident most clearly in the persistent observation of substantial structurally-based health disparities., ${ }^{2,3}$ In creating health disparities, it is apparent that these structural factors represent a powerful context within which more proximal social and behavioral factors more directly affect health.

One important health-related factor that undoubtedly is influenced by social structure is emotional support. Research on the association between emotional support and health has a rich history. ${ }^{4}$ Moreover, the influence of social

Dr Shaw is with the School of Public Health at the University of Albany. Dr Krause and Dr Connell are with the School of Public Health at the University of Michigan. Dr Chatters is with the School of Public Health and School of Social Work at the University of Michigan. Dr Ingersoll-Dayton is with the School of Social Work at the University of Michigan. structure on emotional support and its relationship with health status has received a great deal of attention. ${ }^{5,6}$ The vast majority of this work, however, has concentrated solely on ways in which social structure influences contemporaneous emotional support and health. Underscoring the idea that life events are linked across the life course, a more complete understanding of the influence of social structure on emotional support and health could be gained by assuming a life course perspective. ${ }^{7}$

Researchers are finding increasingly that emotional support received from parents during childhood may have longterm health consequences. ${ }^{8-10}$ According to this research, receiving low levels of parental support during childhood leads to poor health outcomes in adulthood, in part because of disruptions in the development of health-enhancing psychosocial resources, such as personal control beliefs, selfesteem, and other supportive social relationships. ${ }^{11}$ With inadequate personal and social resources, individuals who 
experienced low levels of parental support during childhood may be at risk for ill health throughout their life courses. ${ }^{12,13}$

What is currently not known, however, is the extent to which social structural factors influence the relationship between parental support received early in life and health status later in life. As will be discussed, some current research suggests that levels of parental support received early in life may vary throughout the population as a function of social structural factors. Additionally, although health effects associated with early parental support are evident among some specific groups of adults ${ }^{9,10}$ and the adult population as a whole, ${ }^{8}$ it is unlikely that all adults are affected equally by early life support from parents (or lack thereof). Although some people may experience particularly negative effects resulting from the lack of early parental support, other people may be able to avoid these negative effects. An individual's social structural context may have a major impact on how this long-term process unfolds.

In this article, we intend to establish a more focused understanding of the long-term effects of early parental support by examining the extent to which social structural characteristics shape vulnerability to this early life social exposure. We take two main approaches to identify potentially vulnerable groups. First, we compare the reported prevalence of early parental support across key social structural factors, including gender, race, and SES. This approach will help identify those people who are most likely to experience inadequate parental support during childhood. Next, we compare the degree to which early parental support influences adult health across these same social structural factors. This approach will reveal which individuals are most susceptible to the long-term effects of early parental support.

The discussion that follows is divided into three main sections. First, we discuss the theoretical rationale underlying potential differential vulnerabilities with regard to early parental support. Following this, we describe the sample and measures, and explain the data analytic strategies that we used. Finally, we present the study's findings and discuss conclusions.

\section{Variations in the Amount of Early Parental Support Received}

The social structural context within which early life parent-child relationships take place may either constrain or facilitate the provision of support. For example, structural characteristics, such as gender and race, may have considerable influence on the distribution of early parental support. In addition, the parent-child relationship may be influenced by socioeconomic conditions. We discuss the theoretical underpinnings supporting the potential influence of each of these factors on the distribution of early parental support in later sections of this article.

\section{Gender}

Gender-role socialization processes may be responsible for creating systematic gender disparities, with respect to the receipt of support from parents during childhood. Extensive literature suggests that, beginning in childhood, gender-role socialization practices exert a profound effect on social relationships. ${ }^{14,15}$ Girls are encouraged to form close ties with others and to be attentive to the needs of their affiliates, whereas boys are taught to be competitive, autonomous, and goal-oriented. Parents are a major contributor to this process of socialization. ${ }^{14}$ Thus, it seems that parents, in general, may provide more emotional support to daughters than sons. ${ }^{16}$ And, for similar reasons, mothers may provide more support to their children than do fathers. ${ }^{17}$

\section{Racial Status}

As a result of a history of racial discrimination and restricted opportunities, racial minority groups in America tend to have worse health, less education and income, and fewer psychological resources, such as personal control beliefs, compared with Whites. ${ }^{18,19}$ In response to the unique stressors faced by racial minorities and in an attempt to compensate for a lack of personal resources, it may be that minority parents actually provide more emotional support to their children than do White parents. Indeed, this enhanced focus on familial support and collectivism may be an adaptive strategy used by minority families to promote positive psychological and social development in their children and to protect them from the risks of a racially biased society. ${ }^{20}$

\section{Childhood Socioeconomic Status}

The socioeconomic environment within which a child is raised may also have profound effects on the level of emotional support received from his or her parents. Extensive research suggests that parents who are socioeconomically disadvantaged are more likely to act in an authoritarian rather than supportive manner towards their children than are financially secure parents. ${ }^{21,22}$ For these reasons, individuals who grew up in households of low SES may be expected to have received diminished levels of emotional support from parents during their childhood.

\section{Variations in Associations Between \\ Early Parental Support and Adult Health Status}

The long-term health effects of early parental support are thought to be mediated by the development and maintenance of psychological and social resources. However, the 
psychosocial and health impact of early parental support may be more salient in some contexts than in others.

\section{Gender}

The benefits of receiving abundant parental support and, conversely, the costs of receiving inadequate parental support during childhood may be most powerful within samesex parent-child dyads. The mother-daughter relationship is central in most women's lives. ${ }^{23,24}$ This relationship is a key influence in the identity formation and the long-term psychosocial adjustment of daughters. ${ }^{25-27}$ Likewise, the fatherson relationship is an important influence on the development of men. According to Vogt and Sirridge, ${ }^{28}$ "[the father-son relationship] influences everything in a man's life, from the way he sees himself. . . to the way he sees all other people."28(p. 6) It follows, therefore, that the amount of support a child receives within this same-sex dyad would be a major determinant of psychosocial development and health over an individual's life course.

\section{Racial Status}

Some research suggests that the effects of parental support may be tied less strongly to health outcomes among minorities than it is for Whites. Because ethnic minority children are more likely than White children to mobilize support from kin networks, ${ }^{29}$ perhaps the potentially negative health effects of poor parental support for minorities could be compensated for by abundant support from alternative sources, such as other relatives and friends. For Whites, the support of parents may hold greater weight because it represents a larger proportion of the total support available to a child.

On the other hand, parents may be a critical resource for minority children when dealing with stressors, such as racial discrimination and socioeconomic disadvantage. ${ }^{30}$ Moreover, inadequate parental support during childhood may be a particular risk for poor health among minorities later in life because this early-life disadvantage may have cumulative effects over the life course in combination with other negative environments that are encountered. ${ }^{31}$ Therefore, because minority children may face more challenges during their early development than do White children, as well as more challenges throughout the life course, receiving adequate parental support may be particularly important for their long-term well-being.

\section{Childhood Socioeconomic Status}

The long-term health effects of early parental support may vary also across socioeconomic strata. For example, parental support may be a particularly salient resource for children who are socioeconomically disadvantaged. As the work of Christian and Barbarin ${ }^{32}$ implies, for children living in poor communities, parental support may be a lifeline needed for the development of strong psychosocial resources in the face of socioeconomic difficulties.

Taken together, this review suggests that although receiving early parental support may be an important predictor of mental and physical health outcomes in later life, the impact of early parental support can be fully appreciated only by identifying the social structural factors that are most closely associated with receiving poor support in early life and understanding how associations between levels of support received during childhood and adult health status vary according to these factors. Therefore, the current study addresses the following research questions:

1. Does the amount of early parental support reported vary by gender of the parent, gender of the child, or racial or socioeconomic status?

2. Is the health of women and men differentially associated with early support provided by their mothers or fathers?

3. Are the associations between adult health status and early parental support modified by racial or socioeconomic status?

\section{METHOD}

\section{Sample}

The data for this study come from the National Survey of Midlife Development in the United States (MIDUS), 1995-1996. ${ }^{33}$ Participants were a nationally representative, random-digit-dial sample of noninstitutionalized, Englishspeaking adults, aged 25-74 years, residing in the coterminous United States. Older adults and men were oversampled. The data were collected via an initial telephone interview and a follow-up mailed questionnaire, both of which were completed in 1995. The estimated response rate for the entire MIDUS survey was $60.8 \% .{ }^{33}$ The sample sizes, as well as the descriptive statistics below, are based on weighted data.

A total of 3,044 participants provided data. Of these, 2,786 had complete data on early parental support measures and serve as the base sample. A total of 1,547 respondents (55.5\% of the sample) were women and 1,239 were men. At the time of the survey, the average age of female respondents was 44.81 ( $S D=13.68)$, and the average age of male respondents was $44.58(S D=13.21)$. Approximately $83.7 \%$ of the women and $83.0 \%$ of the men surveyed consider themselves to be White. On average, the men in the sample were slightly more educated than the women were $(M=$ 6.42 and 6.10 , respectively; $t=3.59 ; p<.001$ ). 


\section{Measures}

\section{Early Emotional Support From the Mother and Father}

We constructed separate measures focusing on the availability of emotional support from each parent (or guardian) during childhood. We asked the following questions: (1) "How much did she/he understand your problems and worries?" (2) "How much could you confide in her/him about things that were bothering you?" (3) "How much love and affection did she/he give you?" (4) "How much time and attention did she/he give you when you needed it?" (5) "How much effort did she/he put into watching over you and making sure you had a good upbringing?" and (6) "How much did she/he teach you about life?" We scored each of these items on a 4-point Likert-type scale that included (1) Not at all; (2) A little; (3) Some; and (4) A lot. We summed responses in each subscale, resulting in a scale ranging from 6 to 24, with higher scores indicating more support. The internal consistency reliability for the mother subscale is .90 , whereas the internal consistency reliability of the father subscale is .92 . The correlation between the mother and father subscales is .48. The mean level of support received from mothers is higher than the mean level of support received from fathers (19.08 vs. $16.72 ; t=26.44 ; p<.001)$.

We excluded approximately $8.5 \%$ of the respondents $(N$ $=258$ ) from the study because they failed to respond to at least one of the early parental support items or reported not having been raised by a male and female caregiver while growing up. Clearly, this exclusion of respondents reduces the study's generalizability. It is important to note, however, that these criteria do not necessarily exclude either respondents whose parents divorced or respondents who did not always live with both parents during childhood. Nevertheless, excluding respondents who identified fewer than 2 parental figures is important because the effects of parental absence, on the one hand, and the effects of being raised by a parent who provides no emotional support, on the other hand, may be qualitatively different, although in both cases, effectively no parental support is delivered. When only those respondents with data on 2 parents or caregivers are included, we avoid the potential problems related to comparing respondents with 1 and 2 parents.

\section{Social Structural Factors}

Gender is represented as a binary measure $(1=$ Male; $0=$ Female). Race is treated as an indicator of social status and is conceptualized broadly in terms of majority versus minority racial status. Therefore, it is represented by a binary variable $(1=$ White; $0=$ Non-White $)$. Because of the small numbers of non-White respondents, it was not feasible to break the "Non-White" category into a finer gradation. We used parental education as an indicator of a respondent's SES during childhood. We asked each respondent to report the highest grade or year of schooling completed by each of his or her parents or guardians using a 12point ordinal scale. The correlation between mother's and father's education level is .58. The average level of completed education for both mothers and fathers is 4.6 , which is equivalent to a high school degree. To create a single score representing parental education level, we used the father's education level as the default indicator. If data were not available on a father's education, we used mother's education level. Following this procedure, data on childhood socioeconomic status was available for $96 \%$ of the respondents. Approximately $92 \%$ of these available scores were based upon the father's education, and the remaining $8 \%$ were based upon the mother's education.

\section{Health Outcomes}

Indicators of psychological and physical health in adulthood were the major outcome variables for the current study. We used current depressive symptomatology as an indicator of psychological health. Respondents reported how often during the past 30 days they felt each of 6 different depressive symptoms, including: (1) "So sad that nothing could cheer you up"; (2) "Nervous"; (3) "Restless or fidgety"; (4) "Hopeless"; (5) "That everything was an effort"; and (6) "Worthless." We scored responses to each of these items on a 5-point Likert-type scale ranging from 1 (None of the time) to 5 (All of the time). We computed a total score by summing responses to each of the items. Higher scores indicate more depressive symptoms. The internal consistency reliability estimate for this scale is .87 .

We used a count of current chronic health problems as a measure of physical health status. Respondents reported whether they had experienced or been treated for any of 29 chronic health conditions (eg, asthma, arthritis, thyroid disease, urinary problems, hypertension, or diabetes) in the past 12 months, and whether they had ever had heart trouble or cancer. Approximately $77.3 \%$ of respondents had experienced at least 1 of the 31 conditions, and the average number of conditions across all respondents was $2.71(S D=$ 2.83).

\section{Data Analyses}

The data analyses for this study proceeded in three stages. We assessed levels of support from the mother and father separately throughout these analyses. In the first stage of analysis, we regressed support from the mother and 
father on the key social contextual predictors using ordinary least squares (OLS) regression.

In stage two of the analyses, we assessed gender differences in the associations between early parental support and adult health, again using OLS regression analyses. First, we estimated a basic model representing the potential longterm health effects of receiving support from mothers and fathers during childhood as follows:

$$
\mathrm{CH}=\mathrm{a}+\mathrm{b}_{1} \mathrm{ES}_{\mathrm{M}}+\mathrm{b}_{2} \mathrm{ES}_{\mathrm{F}}+\mathrm{b}_{3} \mathrm{Sex}+\mathrm{z}
$$

where " $\mathrm{CH}$ " refers to current health (ie, depressive symptoms or chronic conditions), "ES ${ }_{\mathrm{M}}$ " stands for early support from the mother, and " $E S_{\mathrm{F}}$ " stands for early support from the father. Additionally, "a" is the intercept, " $b_{i}$ " are regression coefficients, and $\mathrm{z}$ represents the effects of the control variables of race, parental education level, and age. We tested separate models using depressive symptoms and chronic conditions as the dependent variable.

Next, to test the degree to which the effects of support from the mother and support from the father vary according to the gender of the respondent, we entered the interaction terms $\mathrm{ES}_{\mathrm{M}} \times \operatorname{Sex}$ and $\mathrm{ES}_{\mathrm{F}} \times \mathrm{Sex}$ into equation 1. Following the recommendations of Aiken and West,$^{34}$ when we calculated the interaction terms, we centered the independent variables (ES and Sex) on their means. Significant interac- tion terms indicated that the effects of support from the mother or father were different for men and women. Further regression analyses within each gender subgroup revealed the nature of these differences.

The purpose of the third stage of the analyses was to determine the extent to which race and parental education level modify the health effects of early parental support separately for male and female respondents. Specifically, we ran the model depicted in equation 1, excluding the Sex term, within each gender subsample to show the health effects of support from mothers and fathers separately for men and women. Then, we entered the interaction terms $\mathrm{ES}_{\mathrm{M}} \times$ Race and $\mathrm{ES}_{\mathrm{F}} \times$ Race into the model to assess whether the effects of early parental support from each source were different for Whites and non-Whites. Similarly, the interaction terms $\mathrm{ES}_{\mathrm{M}} \times \mathrm{Educ}_{\mathrm{P}}$ and $\mathrm{ES}_{\mathrm{F}} \times \mathrm{Educ}_{\mathrm{P}}$ assessed whether the effects of early parental support varied according to parental education level.

\section{RESULTS}

We present the findings from this current study in three sections corresponding to the Data Analysis plan.

\section{Predictors of Early Parental Support}

Table 1 provides the results of a series of regression analyses estimating the independent associations between

TABLE 1. Regression of Early Parental Support on Demographic and Other Contextual Factors

\begin{tabular}{|c|c|c|c|c|c|c|}
\hline \multirow[b]{2}{*}{ Predictor } & \multicolumn{2}{|c|}{ Males } & \multicolumn{2}{|c|}{ Females } & \multicolumn{2}{|c|}{ Total } \\
\hline & $\beta$ & $B$ & $\beta$ & $B$ & $\beta$ & $B$ \\
\hline \multicolumn{7}{|c|}{ Support from the mother } \\
\hline $\begin{array}{l}\text { Sex }(1=\text { male }) \\
\text { Racial status }(1=\text { White }) \\
\text { Parental education } \\
R^{2} \\
N\end{array}$ & $\begin{array}{c}-.085 * * \\
.016 \\
1.244\end{array}$ & $\begin{array}{r}-.960 \\
.021 \\
99\end{array}$ & $\begin{array}{r}-.056 * \\
.077 * \\
1.571\end{array}$ & $\begin{array}{l}-.679 \\
.124 \\
009\end{array}$ & $\begin{array}{r}.121 * * * \\
-.066^{* * *} \\
.052 * * \\
2.815\end{array}$ & $\begin{array}{r}1.042 \\
-.743 \\
.077 \\
2 .\end{array}$ \\
\hline \multicolumn{7}{|c|}{ Support from the father } \\
\hline $\begin{array}{l}\text { Sex }(1=\text { male }) \\
\text { Racial status }(1=\text { White }) \\
\text { Parental education } \\
R^{2} \\
N\end{array}$ & $\begin{array}{r}-.049 \\
.058 \\
1,205\end{array}$ & $\begin{array}{r}-.615 \\
.093 \\
12\end{array}$ & $\begin{array}{r}-.040 \\
.145^{* * *} \\
1,482\end{array}$ & $\begin{array}{l}-.561 \\
.255 \\
023\end{array}$ & $\begin{array}{r}.021 \\
-.042 * \\
.106 * * * \\
2,687\end{array}$ & $\begin{array}{r}.206 \\
-.566 \\
.181 \\
17\end{array}$ \\
\hline
\end{tabular}

Note. Models were estimated after controlling for respondent age.

$* p<.05 . * * p<.01 . * * * p<.001$. 
early parental support and each of the social structural predictors. Taking the sample as a whole, these results suggest that men $(\beta=.121 ; p<.001)$, non-Whites $(\beta=$ $-.066 ; p<.01)$, and those whose parents were more highly educated $(\beta=.052 ; p<.01)$ reported having received relatively high levels of support from their mothers. Among male respondents only, non-Whites $(\beta=-.085 ; p$ $<.01)$ reported having received more support from a mother than Whites; however, parental education level did not seem to affect the amount of support received from a mother. Among female respondents, relatively low levels of support from mothers were reported by Whites $(\beta=$ $-.056 ; p<.05)$ and by those with low levels of parental education $(\beta=.077 ; p<.05)$.

We did not find any gender differences in the level of support received from fathers in these analyses. Receiving a relatively high level of support from the father, however, was associated with being non-White $(\beta=-.042 ; p<.05)$ and having parents who had completed more years of education $(\beta=$ $.106 ; p<.001)$. The effect of racial status on the level of support received from the father was small and non-significant within each of the gender subgroups. In addition, the association between parental education level and support from the father appeared to exist only among female respondents.

\section{Gender Differences in the Effects of Early Parental Support}

Table 2 presents the results of regression analyses testing for gender differences in the associations between levels of support received from mothers and fathers during childhood and adult health. The left-hand section of the table presents the findings of analyses using depressive symptoms as the outcome, whereas the right-hand section of the table presents the findings from analyses predicting chronic conditions. For both outcomes, Model A examined the simple additive effects and Model B examined the more complex interactions between the gender of the respondent and the source of support.

Beginning in the left-hand portion of the table, the findings from Model A show that increasing levels of support from both mothers $(\beta=-.196 ; p<.001)$ and fathers during childhood $(\beta=-.092 ; p<.001)$ were associated with fewer depressive symptoms in adulthood. In Model B, the multiplicative term testing the interaction between early support from the mother and respondent gender, $\mathrm{ES}_{\mathrm{M}} \times \mathrm{Sex}$, has a significant effect on depressive symptoms in this model ( $\beta$ $=.157 ; p<.001)$. The positive sign on this effect suggests that the inverse relationship between early support from the mother and adult depressive symptoms is less substantial among male respondents. The interaction between respondent gender and the effects of early support from the father also appears to have a significant effect on depressive symptoms $(\beta=-.075 ; p<.05)$. Here, the negative sign suggests that the inverse relationship between early support from the father and adult depressive symptoms was more substantial among male respondents than female respondents.

We find somewhat similar results in predicting adult chronic conditions. As shown in Model A on the right-hand

TABLE 2. Regression of Adult Health on Early Parental Support and Social Structural Factors

\begin{tabular}{|c|c|c|c|c|c|c|c|c|}
\hline \multirow[b]{3}{*}{ Predictor } & \multicolumn{4}{|c|}{ Depressive symptoms } & \multicolumn{4}{|c|}{ Chronic health conditions } \\
\hline & \multicolumn{2}{|c|}{ Model A } & \multicolumn{2}{|c|}{ Model B } & \multicolumn{2}{|c|}{ Model A } & \multicolumn{2}{|c|}{ Model B } \\
\hline & $\beta$ & $B$ & $\beta$ & $B$ & $\beta$ & $B$ & $\beta$ & $B$ \\
\hline $\operatorname{Sex}(1=$ male $)$ & $-.093 * * *$ & -.723 & $-.096 * * *$ & -.750 & $-.127 * * *$ & -.706 & $-.130 * * *$ & -.722 \\
\hline Racial status $(1=$ White $)$ & -.021 & -.224 & -.019 & -.205 & -.001 & -.004 & .001 & .005 \\
\hline Parental education & -.013 & -.017 & -.012 & -.016 & -.016 & -.015 & -.016 & -.015 \\
\hline Support from the mother $\left(\mathrm{ES}_{\mathrm{M}}\right)$ & $-.196 * * *$ & -.180 & $-.178 * * *$ & -.163 & $-.143 * * *$ & -.093 & $-.128 * * *$ & -.083 \\
\hline Support from the father $\left(\mathrm{ES}_{\mathrm{F}}\right)^{\mathrm{M}}$ & $-.092 * * *$ & -.073 & $-.102 * * *$ & -.081 & -.002 & -.001 & -.012 & -.007 \\
\hline $\mathrm{ES}_{\mathrm{M}} \times \mathrm{Sex}$ & - & - & - & $.157 * * * \dagger$ & - & - & - & $.089 * * *$ \\
\hline $\mathrm{ES}_{\mathrm{F}}^{\mathrm{M}} \times \mathrm{Sex}$ & \multirow{2}{*}{\multicolumn{2}{|c|}{.089}} & - & $-.075^{*}$ & - & - & - & $-.062 *$ \\
\hline$R^{2^{\Gamma}}$ & & & \multicolumn{2}{|c|}{.094} & \multicolumn{2}{|c|}{.094} & \multicolumn{2}{|c|}{.097} \\
\hline$N$ & \multicolumn{2}{|c|}{2,606} & \multicolumn{2}{|c|}{2,606} & \multicolumn{2}{|c|}{2,633} & \multicolumn{2}{|c|}{2,633} \\
\hline
\end{tabular}

Note. Models were estimated after controlling for respondent age.

$\dagger$ Unstandardized coefficients are reported when focusing on the multiplicative terms because standardized estimates are meaningless in this context. $* p<.05 . * * p<.01 . * * * p<.001$. 
side of Table 2, an increased level of support from the mother was associated with fewer chronic conditions during adulthood $(\beta=-.143 ; p<.001)$. However, the level of support received from the father during childhood did not appear to be associated with the number of chronic conditions an adult experienced. In addition, as we found in the models predicting depressive symptoms, respondent gender modified the effects of early parental support on adult chronic conditions. The interaction effect for early support from the mother and gender was positive $(\beta=.089 ; p<.01)$, suggesting that the effect of support from the mother on chronic conditions was weaker among male respondents. Conversely, the interaction effect for early support from the father and respondent gender was negative $(\beta=-.062 ; p<$ $.05)$, suggesting that the association between early support from the father and chronic conditions was stronger among male respondents. Although there did not appear to be an association between early support from the father and chronic conditions for the sample as a whole, this type of support may have important links to the development of chronic conditions among men.

\section{Other Social Contextual Modifiers}

We performed the analyses in this section separately for men and women. Table 3 shows the effects of early support from mothers and fathers on depressive symptoms and chronic health conditions among men. Model A shows the main effects of early parental support on depressive symptoms. Receiving abundant support from the father during childhood was associated with fewer depressive symptoms

TABLE 3. Regression of Depressive Symptoms and Chronic Health Conditions on Early Parental Support and Demographic and Contextual Factors-Males

\begin{tabular}{|c|c|c|c|c|c|c|}
\hline \multirow[b]{2}{*}{ Predictor } & \multicolumn{2}{|c|}{ Model A } & \multicolumn{2}{|c|}{ Model B } & \multicolumn{2}{|c|}{ Model C } \\
\hline & $\beta$ & $B$ & $\beta$ & $B$ & $\beta$ & $B$ \\
\hline \multicolumn{7}{|c|}{ Depressive symptoms $(\mathrm{N}=1,176)$} \\
\hline $\begin{array}{l}\text { Racial status }(1=\text { White }) \\
\text { Parental education }\left(\text { Educ }_{\mathrm{P}}\right) \\
\text { Support from the mother }\left(\mathrm{ES}_{\mathrm{M}}\right) \\
\text { Support from the father }\left(\mathrm{ES}_{\mathrm{F}}\right) \\
\mathrm{ES}_{\mathrm{M}} \times \text { racial status } \\
\mathrm{ES}_{\mathrm{F}} \times \text { racial status } \\
\mathrm{ES}_{\mathrm{M}} \times \text { Educ }_{\mathrm{P}} \\
\mathrm{ES}_{\mathrm{F}} \times \text { Educ }_{\mathrm{P}} \\
R^{2}\end{array}$ & $\begin{array}{l}.043 \\
.008 \\
-.078^{*} \\
-.167^{* * *} \\
- \\
- \\
- \\
-\end{array}$ & $\begin{array}{r}.393 \\
.009 \\
-.070 \\
-.122 \\
- \\
- \\
-\end{array}$ & $\begin{array}{c}.041 \\
.007 \\
-.078^{*} \\
-.167 * * * \\
- \\
- \\
- \\
-\end{array}$ & $\begin{array}{c}.375 \\
.008 \\
-.070 \\
-.121 \\
.026 \dagger \\
.014 \\
- \\
-\end{array}$ & $\begin{array}{c}.044 \\
.010 \\
-.083^{*} \\
-.162^{* *} \\
- \\
- \\
-\end{array}$ & $\begin{array}{r}.401 \\
.012 \\
-.075 \\
-.118 \\
- \\
-.015 \\
.008\end{array}$ \\
\hline & \multicolumn{2}{|c|}{ Model D } & \multicolumn{2}{|c|}{ Model E } & \multicolumn{2}{|c|}{ Model F } \\
\hline Predictor & $\beta$ & $B$ & $\beta$ & $B$ & $\beta$ & $B$ \\
\hline \multicolumn{7}{|c|}{ Chronic health conditions $(\mathrm{N}=1,184)$} \\
\hline $\begin{array}{l}\text { Racial status }(1=\text { White }) \\
\text { Parental education }\left(\text { Educ }_{\mathrm{P}}\right) \\
\text { Support from the mother }\left(\mathrm{ES}_{\mathrm{M}}\right) \\
\text { Support from the father }\left(\mathrm{ES}_{\mathrm{F}}\right) \\
\mathrm{ES}_{\mathrm{M}} \times \text { racial status } \\
\mathrm{ES}_{\mathrm{F}} \times \text { racial status } \\
\mathrm{ES}_{\mathrm{M}} \times \text { Educ }_{\mathrm{P}} \\
\mathrm{ES}_{\mathrm{F}} \times \text { Educ }_{\mathrm{P}} \\
R^{2}\end{array}$ & $\begin{array}{c}.022 \\
-.027 \\
-.051 \\
-.079 * \\
- \\
- \\
- \\
-\end{array}$ & $\begin{array}{r}.141 \\
-.023 \\
-.033 \\
-.041 \\
- \\
- \\
-\end{array}$ & $\begin{array}{c}.023 \\
-.025 \\
-.050 \\
-.082 * \\
- \\
- \\
- \\
-\end{array}$ & $\begin{array}{r}.146 \\
-.021 \\
-.032 \\
-.042 \\
.013 \\
-.058 \\
- \\
-\end{array}$ & $\begin{array}{c}.024 \\
-.024 \\
-.054 \\
-.078^{*} \\
- \\
- \\
-\end{array}$ & $\begin{array}{r}.152 \\
-.020 \\
-.035 \\
-.040 \\
- \\
-.007 \\
.003\end{array}$ \\
\hline
\end{tabular}

Note. Models were estimated after controlling for respondent age.

$\dagger$ Unstandardized coefficients are reported when focusing on the multiplicative terms because standardized estimates are meaningless in this context. $* p<.05 . * * p<.01 . * * * p<.001$. 
in adulthood among men $(\beta=-.167 ; p<.001)$. Having received abundant support from the mother during childhood also appeared to protect adult men from developing depressive symptoms $(\beta=-.078 ; p<.05)$. However, the association between early support from the father and adult depressive symptoms was more than twice as strong as the association between early support from the mother and adult depressive symptoms within the male sample.

The opposite was true within the female sample. Table 4 shows the effects of early support from mothers and fathers on adult depressive symptoms and chronic health conditions among women. Here again, receiving abundant support from the father was associated with a decreased level of depressive symptoms during adulthood $(\beta=$ $-.059 ; p<.05)$; however, receiving support from the mother during childhood was associated much more strongly associated with depressive symptoms during adulthood $(\beta=-.253 ; p<.001)$. This set of results is consistent with the interaction terms estimated in Table 2. The level of early support from the father seemed to be linked more strongly to adult depression among men, whereas the level of early support from the mother seemed to be linked more strongly to adult depression among women.

Models B and C of Table 3 estimate the extent to which the main effects of early parental support on adult depression among men were modified by racial status and parental education level. These findings show that, among men, neither of these factors modified the health effects of early support from either the mother or father. This means that, among adult men, early support from the mother and father was associated with fewer current depressive symptoms, regardless of racial status or parental education level.

TABLE 4. Regression of Depressive Symptoms and Chronic Health Conditions on Early Parental Support and Demographic and Contextual Factors-Females

\begin{tabular}{|c|c|c|c|c|c|c|}
\hline \multirow[b]{2}{*}{ Predictor } & \multicolumn{2}{|c|}{ Model A } & \multicolumn{2}{|c|}{ Model B } & \multicolumn{2}{|c|}{ Model C } \\
\hline & $\beta$ & $B$ & $\beta$ & $B$ & $\beta$ & $B$ \\
\hline \multicolumn{7}{|c|}{ Depressive symptoms $(\mathrm{N}=1,431)$} \\
\hline $\begin{array}{l}\text { Racial status }(1=\text { White }) \\
\text { Parental education }\left(\text { Educ }_{\mathrm{P}}\right) \\
\text { Support from the mother }\left(\mathrm{ES}_{\mathrm{M}}\right) \\
\text { Support from the father }\left(\mathrm{ES}_{\mathrm{F}}\right) \\
\mathrm{ES}_{\mathrm{M}} \times \text { racial status } \\
\mathrm{ES}_{\mathrm{F}} \times \text { racial status } \\
\mathrm{ES}_{\mathrm{M}} \times \text { Educ }_{\mathrm{P}} \\
\mathrm{ES}_{\mathrm{F}} \times \text { Educ }_{\mathrm{P}} \\
R^{2}\end{array}$ & $\begin{array}{l}-.062^{*} \\
-.022 \\
-.253^{* * * *} \\
-.059 \\
- \\
- \\
- \\
-\end{array}$ & $\begin{array}{r}-.726 \\
-.033 \\
-.234 \\
-.049 \\
- \\
- \\
-\end{array}$ & $\begin{array}{l}-.065^{*} \\
-.022 \\
-.257^{* * *} \\
-.061^{*} \\
- \\
- \\
- \\
-\quad \\
\quad .0\end{array}$ & $\begin{array}{l}-.755 \\
-.032 \\
-.237 \\
-.050 \\
.199 * * \dagger \\
-.101 \\
- \\
-\end{array}$ & $\begin{array}{l}-.062^{*} \\
-.021 \\
-.254^{* * *} \\
-.060^{*} \\
- \\
- \\
- \\
-\end{array}$ & $\begin{array}{r}-.719 \\
-.030 \\
-.234 \\
-.050 \\
- \\
-.005 \\
-.003\end{array}$ \\
\hline & \multicolumn{2}{|c|}{ Model D } & \multicolumn{2}{|c|}{ Model E } & \multicolumn{2}{|c|}{ Model F } \\
\hline Predictor & $\beta$ & $B$ & $\beta$ & $B$ & $\beta$ & $B$ \\
\hline \multicolumn{7}{|c|}{ Chronic health conditions $(\mathrm{N}=1,431)$} \\
\hline $\begin{array}{l}\text { Racial status }(1=\text { White }) \\
\text { Parental education }\left(\text { Educ }_{\mathrm{P}}\right) \\
\text { Support from the mother }\left(\mathrm{ES}_{\mathrm{M}}\right) \\
\text { Support from the father }\left(\mathrm{ES}_{\mathrm{F}}\right) \\
\mathrm{ES}_{\mathrm{M}} \times \text { racial status } \\
\mathrm{ES}_{\mathrm{F}} \times \text { racial status } \\
\mathrm{ES}_{\mathrm{M}} \times \text { Educ }_{\mathrm{P}} \\
\mathrm{ES}_{\mathrm{F}} \times \text { Educ }_{\mathrm{P}} \\
R^{2}\end{array}$ & $\begin{array}{l}-.015 \\
-.007 \\
-.187 * * * \\
.034 \\
- \\
- \\
-\end{array}$ & $\begin{array}{r}-.121 \\
-.007 \\
-.123 \\
.002 \\
- \\
- \\
-\end{array}$ & $\begin{array}{l}-.014 \\
-.006 \\
-.186^{* * *} \\
-.035 \\
-.038 \\
.017 \\
- \\
-\end{array}$ & $\begin{array}{r}-.115 \\
-.007 \\
-.122 \\
-.020 \\
- \\
- \\
-\end{array}$ & $\begin{array}{l}-.014 \\
-.010 \\
-.185 * * * \\
.032 \\
- \\
- \\
- \\
-\end{array}$ & $\begin{array}{r}-.114 \\
-.011 \\
-.121 \\
.019 \\
- \\
-.013^{*} \\
.010\end{array}$ \\
\hline
\end{tabular}

Note. Models were estimated after controlling for respondent age.

$\dagger$ Unstandardized coefficients are reported when focusing on the multiplicative terms because standardized estimates are meaningless in this context. $* p<.05 . * * p<.01 . * * * p<.001$. 
A parallel set of analyses for female respondents appears in Table 4. As is the case within the male subsample, Model $\mathrm{C}$ shows that among women, the associations between depressive symptoms and early support from the mother and father were invariant across parental education level. However, Model B shows that the effect of early support from the mother on adult depressive symptoms did appear to differ between majority and minority racial status $(B=.199 ; p<$ .010). The positive sign of this effect suggests that the association between depressive symptoms and early support from the mother was less apparent among White respondents compared with non-White respondents taken as a whole.

Models D, E, and F of Tables 3 and 4 show the effects of early parental support on adult chronic health conditions among men and women, respectively. As shown in Model D of Table 3, among men, having received early support from the father was associated with a reduced burden of chronic conditions during adulthood $(\beta=-.079 ; p<.05)$. The level of early support from the mother, however, did not appear to be associated with chronic conditions among adult men. And again, the opposite is true for female respondents. Specifically, as shown in Model D of Table 4, having received abundant support from the mother during childhood seemed to help adult women avoid developing chronic conditions ( $\beta=$ $-.187 ; p<.001)$. However, receiving support from the father early in life did not appear to influence the number of chronic conditions women experienced later in life.

Additional findings presented in Table 3 show that, for men, the health effects of early parental support were invariant across respondent racial status and parental education level (Models E and F). Among women, the long-term health effects of early parental support also appeared to be relatively invariant, with one exception. As shown in Model $\mathrm{F}$ of Table 4, the negative effect of the interaction term, "ES ${ }_{\mathrm{M}} \times$ Educ $_{\mathrm{P}}$ " suggests that the protective effects of early support from the mother appeared to be slightly greater among those respondents with more highly educated parents $(B=-.013 ; p<.05)$.

\section{COMMENT}

This study makes an important contribution to our growing understanding of the association between the receipt of parental support during childhood and adult health status. By identifying key social structural factors that are associated with receiving inadequate parental support during childhood and the structural conditions within which associations between early parental support and adult health occur, the scope and nature of this association are brought into focus. The findings of this study should provide valuable information needed for targeting and tailoring intervention efforts related to early parental support and successful aging.

With respect to predictors of early parental support, this study has several noteworthy findings. Contrary to what was predicted, men reported having received more support from mothers during childhood than did women. Additional work is necessary, however, to explain this difference. If women are more prone to receiving low levels of support during childhood than are men, intervention efforts aimed at increasing maternal support specifically for girls during childhood may be warranted.

The current study also reveals that individuals from high SES families (as indexed by parental education level) report having received more early parental support than those with relatively low SES during childhood. This finding suggests an interesting question for future research: Do socioeconomic disparities in adult health stem, at least in part, from disparities in parental support received during childhood? In contrast, the finding that non-Whites reported higher levels of early parental support than Whites suggests that racial disparities in health during adulthood may not be easily traced back to early parental support. The current findings are consistent with previous work showing higher levels of parental support among some non-White groups, such as African Americans. ${ }^{35}$ In fact, providing particularly high levels of early parental support may be one way in which minority families prepare children to cope with the structural disadvantages and discrimination encountered throughout the life course, ${ }^{20}$ thus potentially suppressing the development of racial disparities in adult health.

Regarding the influence of social structural factors on the associations between early parental support and adult health status, the current findings emphasize the critical and pervasive impact of gender in our culture. Of the three social structural factors examined, gender appears to play an especially important role in shaping the influence of early parental support across the life course. On the whole, early support from the mother is tied more strongly to adult health than is early support from the father; support from the mother is particularly important for the adult health of women. In contrast, support from the father is particularly important for the health of men throughout the adult life course. These findings suggest that women who received inadequate support from their mothers and men who received inadequate support from their fathers may be most at risk for developing negative health outcomes.

Aside from these gender differences, the association between early parental support and health in later life is largely unaffected by the other social structural factors. Early parental support appears to predict adult health 
regardless of minority status or childhood SES. This suggests that early parental support is a critical resource across a variety of structural contexts.

One exception to this pattern involves early support from the mother and adult depression among women. Apparently, early maternal support is a better predictor of adult depressive symptoms for minority women than it is for White women. This lends some support to the idea that parental support is an especially critical resource for the development of minority children. ${ }^{31}$

Another significant interaction effect involves the association between maternal support and chronic conditions among females. Apparently the health effects of support received from the mother are especially strong among women with relatively advantaged socioeconomic origins. This finding suggests that, in some cases, the detrimental effects of growing up in a socioeconomically disadvantaged environment eclipse, rather than exacerbate, the health effects of early parental support. That is, perhaps the importance of early support from the mother is overshadowed within the challenging context of disadvantaged socioeconomic conditions. Additional research is needed to corroborate this finding.

In view of these potentially important findings, the limitations of the study should also be recognized. First, data about parental support received during childhood were collected from adults at 1 point in time. Therefore, given the age range in our sample (25-74), some study subjects were asked to recall events that may have occurred up to a half century ago. This study design raises the possibility of 2 types of error in measuring early parental support. First, simply because of the passage of time between childhood and adulthood, some adults may have trouble remembering events or conditions from their childhood. Second, this study design allows for the possibility of confounding between the study's health outcomes and reports of early parental support. ${ }^{36}$ In particular, one could argue that respondents' current health status may differentially influence how they respond to questions about their past social environments.

Despite these concerns about the accuracy of self-reported long-term recall of childhood experiences, there is mounting evidence that bias in recalling experiences from childhood may not be as great as some fear. ${ }^{37,38}$ In fact, after reviewing the literature, Brewin, Andrews, and Gotlib ${ }^{39}$ conclude that claims about the unreliability of retrospective reports of adverse childhood experiences are "exaggerated." (p.82) Furthermore, other research provides evidence for the accuracy of retrospective reports of early parental support, in particular. Using the Parental Bonding Instrument, ${ }^{40}$ Parker, Turpling, and Brown have shown that retrospective ratings of early parental support made by adult children are corroborated by separate reports from their parents. ${ }^{41}$ Moreover, both of these ratings, rather than just the ratings from adult children, are significantly associated significantly with levels of depression in the adult children. Similarly, more recent research shows that siblings also provide a high level of corroboration of retrospective reports of childhood adversity. ${ }^{42}$ Of course, this level of corroboration does not prove that retrospective reporting of early parental support is always accurate because a parent's or sibling's retrospective rating of the support that parents provided to a child could also be influenced by the adult child's current health status. Unfortunately, however, without 3 or more waves of data it is not possible to disentangle the direction of effects between reports of early parental support and adult health.

In addition, the response rate for the MIDUS is somewhat low $(60.8 \%)$. This calls into question the representativeness of the study sample. In particular, previous studies using this data suggest that the MIDUS sample underrepresents minorities and those with low income and education. ${ }^{43}$ Although we weighted the data in order to correct for this sampling bias, the generalizability of the study's findings should be examined further.

The adequacy with which this study was able to make racial comparisons regarding early parental support and its effects on health is also constrained. For instance, it is impossible to know from this study whether the racial differences regarding early parental support reflect true differences in the amount of support received and its effects or rather differences in interpretations and perceptions of support behaviors. In addition, a complete picture of racial and ethnic differences regarding early parental support cannot be fully developed when all non-White respondents are grouped together, as was the case in the current study. Grouping these respondents together improves the statistical power available for analyses; however, as a consequence, between-group comparisons among minority populations cannot be made. Future work in this area should address this critical gap.

Finally, the scope of the current study also did not allow for the examination of other closely related and important research questions. For example, we did not assess the degree to which support from a suitable nonparental substitute can offset the potentially harmful effects of low parental support in the current study. Also, the extent to which the relationship between early parental support and adult health is confounded by parents' own health during the respondent's childhood could not be addressed.

Despite these limitations, the findings from the current study are meaningful. The observation that the long-term 
health effects of early parental support vary strongly by gender, but not appreciably by other social contextual factors, provides valuable information about the nature and potential robustness of this social determinant of health over the life course. Although it is becoming increasingly clear that parental support received during childhood appears to be an important social resource linked to long-term health outcomes, the current study suggests that support received from a same-sex parent may be essential. Moreover, the importance of this early life resource is evident across diverse socioeconomic and racial contexts, suggesting that it may be somewhat of a universal necessity for attaining positive health outcomes across the life course. Finally, the finding that children from lower SES families are at increased risk for receiving low levels of this important resource reveals a potentially interesting new explanation for the development of socioeconomic-based health disparities across the life course.

\section{ACKNOWLEDGMENTS}

This research was supported by a grant from the National Institute on Aging ("Well-Being Among the Aged: Personal Control and Self-Esteem,” R01 AG09221, Principal Investigator: Neal Krause).

\section{REFERENCES}

1. Link BG, Phelan JC. Editorial: understanding sociodemographic differences in health - the role of fundamental social causes. Am J Public Health. 1996;86:471-473.

2. House JS, Williams DR. Understanding and reducing socioeconomic and racial/ethnic disparities in health. In: Smedley BD, Syme SL, eds. Promoting Health: Intervention Strategies From Social and Behavioral Research. Washington, DC: National Academy Press; 2000: 81-124.

3. McDonough P, Walter V. Gender and health: reassessing patterns and explanations. Soc Sci Med. 2001;52:547-559.

4. House JS, Kahn R. Measures and concepts of social support. In: Cohen S, Syme SL, eds. Social Support and Health. Orlando, FL: Academic Press; 1985: 83-103.

5. Fuhrer R, Stansfeld SA. How gender affects patterns of social relations and their impact on health: a comparison of one or multiple sources of support from "close persons." Soc Sci Med. 2002;54:811-25.

6. Turner RJ, Marino F. Social support and social structure: a descriptive epidemiology. J Health Soc Beh. 1994;35:193-212.

7. George LK. Missing links: the case for a social psychology of the life course. The Gerontologist. 1996;36:248-55.

8. Enns MW, Cox BJ, Clara I. Parental bonding and adult psychopathology: results from the US National Comorbidity Survey. Psychol Med. 2002;32:997-1008.

9. Richman JA, Flaherty JA. Childhood relationships, adult coping resources and depression. Soc Sci Med. 1986;23:709-716.

10. Russek LG, Schwartz GE. Perceptions of parental caring predict health status in midlife: a 35-year follow-up of the Har- vard Mastery of Stress study. Psychosom Med. 1997;59: 144-149.

11. Bowlby J. Attachment and Loss, Volume III. New York: Basic Books; 1980.

12. Bandura A. Self-efficacy in Changing Societies. New York: Cambridge University Press; 1995.

13. Berkman LF. The role of social relations in health promotion. Psychosom Med.1995;57:245-254.

14. Gore S, Colten ME. Gender, stress, and distress: social-behavioral influences. In: Eckenroade J, ed. The Social Context of Coping. New York: Plenum; 1991: 139-163.

15. Rosenfield S, Vertefuille J, McAlpine DD. Gender stratification and mental health: an exploration of dimensions of the self. Soc Psychol Quart. 2000;63:208-223.

16. Barbee AP, Cunningham MR, Winstead BA, et al. Effects of gender role expectations on the social support process. $J$ Soc Issues. 1993;49:175-190.

17. Gilligan C. In a Different Voice: Psychological theory and women's development. Cambridge, MA: Harvard University Press: 1982.

18. Livingston IL. Handbook of Black American Health: The Mosaic of Conditions, Issues, Policies, and Proposals. Westport, CT: Greenwood Press: 1994.

19. Shaw BA, Krause N. Exploring race variations in aging and personal control. J Gerontol Soc Sci. 2001;56B:S119-S124.

20. Baldwin JA, Hopkins R. African-American and EuropeanAmerican cultural differences as assessed by the worldviews paradigm: an empirical analysis. West $J$ Black Studies. 1990;14:38-52.

21. Kohn ML, Naoi A, Schoenbach C, et al. Position in the class structure and psychological functioning in the United States, Japan, and Poland. Am J Sociology. 1990;95:964-1008.

22. McLoyd VC. Socioeconomic disadvantages and child development. Am Psychol. 1998;53:185-204.

23. Steinberg L. Recent research on the family at adolescence: The extent and nature of sex differences. J Youth Adolesc. 1987;16:191-197.

24. Herman N. Too Long a Child: The Mother-Daughter Dyad. London: Free Association Books; 1989.

25. Debold E, Wilson M, Malave I. Mother and Daughter Revolution: Good Girls to Great Women. Sydney: Doubleday; 1993.

26. Miller JB. The development of women's sense of self. In: Zanardi C, ed. Essential Papers on the Psychology of Women. New York: New York University Press; 1991: 437-454.

27. Surrey J. Self-in-relations: a theory of women's development. Adv Dev. 1993;5:1-11.

28. Vogt GM, Sirridge ST. Like Son, Like Father: Healing the Father-Son Wound in Men's Lives. New York: Plenum; 1991.

29. Del Carmen R, Virgo GN. Marital disruption and nonresidential parenting: A multicultural perspective. In: Depner C, Bray J, eds. Nonresidential Parenting: New Vistas in Family Living. Newbury Park, CA: Sage; 1993: 13-36.

30. McCabe KM, Clark R, Barnett D. Family protective factors among urban African American youth. J Clin Child Psychol. 1999;28:137-150. 
31. Jackson JS, Chatters LM, Taylor RJ. Aging in Black America. Thousand Oaks, CA: Sage; 1993.

32. Christian MD, Barbarin OA. Cultural resources and psychological adjustment of African American children: effects of spirituality and racial attribution. J Black Psychol. 2001;27:43-63.

33. Brim OG, Baltes PB, Bumpass LL, et al. National Survey of Midlife Development in the United States (MIDUS), 1995-1996. Cambridge, MA: Harvard Medical School, Department of Health Care Policy; 1996.

34. Aiken LS, West SG. Multiple Regression: Testing and Interpreting Interactions. Newbury Park, CA: Sage Publications, Inc.; 1991.

35. Maton KI, Teti DM, Corns CM. Cultural specificity of support sources, correlates and contexts: three studies of African American and Caucasian youth. Am J Community Psychol. 1996;24:551-587.

36. Maughan B, Rutter M. Retrospective reporting of childhood adversity: Issues in assessing long-term recall. J Personal Disord. 1997;11:19-23.
37. Bernstein DP, Fink L, Handelsman L, et al. Initial reliability and validity of a new retrospective measure of child abuse and neglect. Am J Psychiatry. 1994;151:1132-1136.

38. Dill DL, Chu JA, Grob MC, Eisen SV. The reliability of abuse history reports: A comparison of two inquiry formats. Compr Psychiatry. 1991:32:166-169.

39. Brewin CR, Andrews B, Gotlib IH. Psychopathology and early experience: A reappraisal of retrospective reports. Psychol Bull. 1993;113:82-98.

40. Parker G, Tupling H, Brown LB. A parental bonding instrument. J Med Psychol. 1979;52:1-10.

41. Parker G. Parental "affectionless control" as an antecedent to adult depression: a risk factor delineated. Arch Gen Psychiatry. 1983;40:956-960.

42. Bifulco A, Brown GW, Lillie A, Jarvis J. Memories of childhood neglect and abuse: corroboration in a series of sisters. $J$ Child Psychol Psychiatry. 1997;38:365-374.

43. Lachman, ME, West SL. Socioedemographic variations in the sense of control by domain: Findings from the MacArthur Studies of Midlife. Psychol Aging. 1998;13:553-562. 
Copyright of Behavioral Medicine is the property of Heldref Publications and its content may not be copied or emailed to multiple sites or posted to a listserv without the copyright holder's express written permission. However, users may print, download, or email articles for individual use. 